\title{
The Impact of Urban Complex Function Zoning on Traffic
}

\author{
Lijiao Liu ${ }^{1, a}$ and Jihui Ma ${ }^{1,2, b}$ \\ ${ }^{1}$ School of Traffic and Transportation, Beijing Jiaotong University, Beijing 100044, China \\ ${ }^{2}$ MOE Key Laboratory for Urban Transportation Complex Systems Theory and Technology, Beijing \\ Jiaotong University, Beijing 100044, China \\ a16120766@bjtu.edu.cn, bjhma@bjtu.edu.cn
}

Keywords: Urban complex; Functional zoning; Internal and external traffic; Traffic impact

\begin{abstract}
Urban complex is a new type of urban organization, which is highly efficient, highly efficient and convenient to use land resources. The purpose of this paper is to explore the influence of different functions of urban complex on the traffic inside and outside the city. Based on the analysis of the features of urban complex, this paper analyzes the effects of different functions on the traffic generation, trip mode, traffic peak hour, parking demand. This paper analyzes the impact of functional planning of Qingdao city Huangdao District Wanda East cinema to traffic. It is of great significance to enrich the research content of urban traffic impact assessment, and to improve the internal and external traffic environment.
\end{abstract}

\section{Introduction}

The urban complex has the features of highly complex function, high degree of land utilization, and building cluster. As a new type of building products, the traffic problem is becoming more and more obvious [1]. A large number of scholars have studied the influence of the location and function space of urban complex on traffic. "Machu Picchu charter" pointed out that the city should be designed as a whole, and should not be considered separately from the various functions of the city zone. "Land Mass Impact Assessment Manual" [2] analysis of the urban complex land mass and study the impact of the traffic [3]. Wang Wei's theory and method of urban transportation planning summarizes the relevant theories of urban planning and transportation. Dr. Li Lei reveals the six characteristics of the urban complex as an open architecture system in the traffic organization, functional composition, morphological characteristics, economic cycle and cultural system and ecological sustainable development [4]. This paper analyzes the impact of urban complex on traffic generation, traffic travel mode, traffic peak hour, parking demand [5]. Urban complex provides convenience, but also raises the traffic problem [6]. To provide a theoretical reference for urban planners, so that the layout and function of urban complex coordination with urban traffic.

\section{The Concept of Urban Complex Traffic and the Characteristics of Internal and External Traffic}

Urban complex traffic is shown in Fig. 1. According to the choice of passenger travel mode is divided into internal and external traffic. 


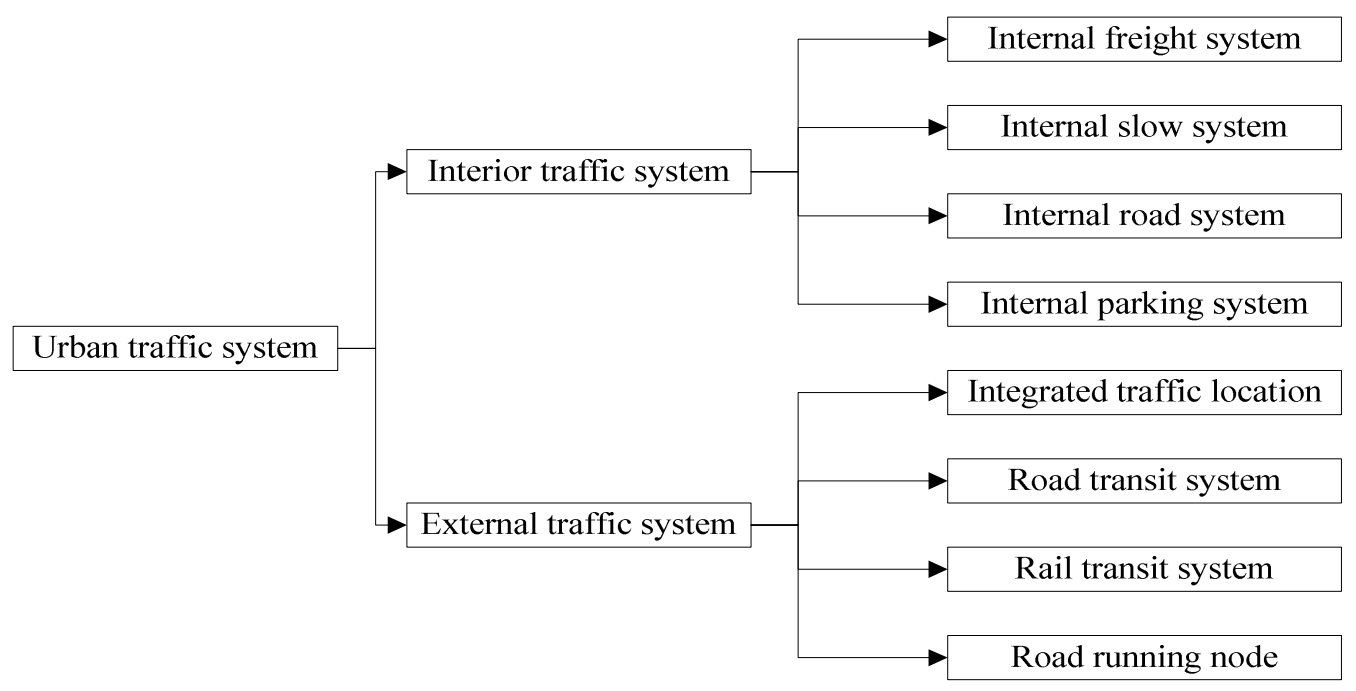

Figure 1. Urban complex traffic system framework

Internal Traffic of Urban Complex. The internal traffic of the urban complex is composed of ground sidewalk, commercial street, air bridge, trail, underground passage, city square and so on. Each function of the urban complex is permeated with certain traffic function[7].

External Traffic of Urban Complex. The origin or the destination of the trip is located outside the urban complex[8].

The internal traffic of urban complex should be connected with the external traffic effectively to improve the accessibility of urban complex traffic system.

\section{The Influence of Functional Planning on Urban Traffic}

The urban complex has a higher demand for the carrying capacity of the internal and external traffic, and has a certain impact on [9].

Effect of Functional Zoning on Traffic Trip Generation. This paper is aimed at the prediction of traffic generation of several typical urban complex functions, in order to analyze the influence of various functions of urban complex on traffic[10].

1) Residential function traffic trip generation forecast

$$
Q_{r s}=S_{r} K_{s} E_{r} X / P N_{r s}
$$

Where $Q_{r s}$ is residential function area peak hour car forecast traffic volume. $S_{r}$ is residential area of functional area. $K_{s}$ is travel proportion coefficient of vehicle quantity(Value is $82 \%$ ). $E_{r}$ is the number of residents daily travel(Value is 2.7). $X$ is peak hour factor(Value is 0.24 ). $P$ is average floor area per person(Value is 12). $N_{r s}$ is number of passengers per vehicle(Value is 2.1).

2) Business function traffic trip generation forecast

$$
Q_{b s}=A_{s} \alpha_{b s}
$$

$Q_{b s}$ is peak hour volume. $A_{s}$ is area of structure. $\alpha_{b s}$ is peak hour rate(Value is 0.26).

Influence of Functional Zoning on Traffic Trip Mode. Different travel purposes determine the different travel modes. There are many ways to travel, including walking, bicycles, cars, taxis, buses, subway, light rail, etc. According to the purpose of travel, residents choose their own way of travel, if necessary, need to transfer.

Effect of Functional Zoning on Traffic Peak Hours. The traffic peak hour is shown in Fig. 2. Different functional types of urban complexes have different traffic peak hour. 


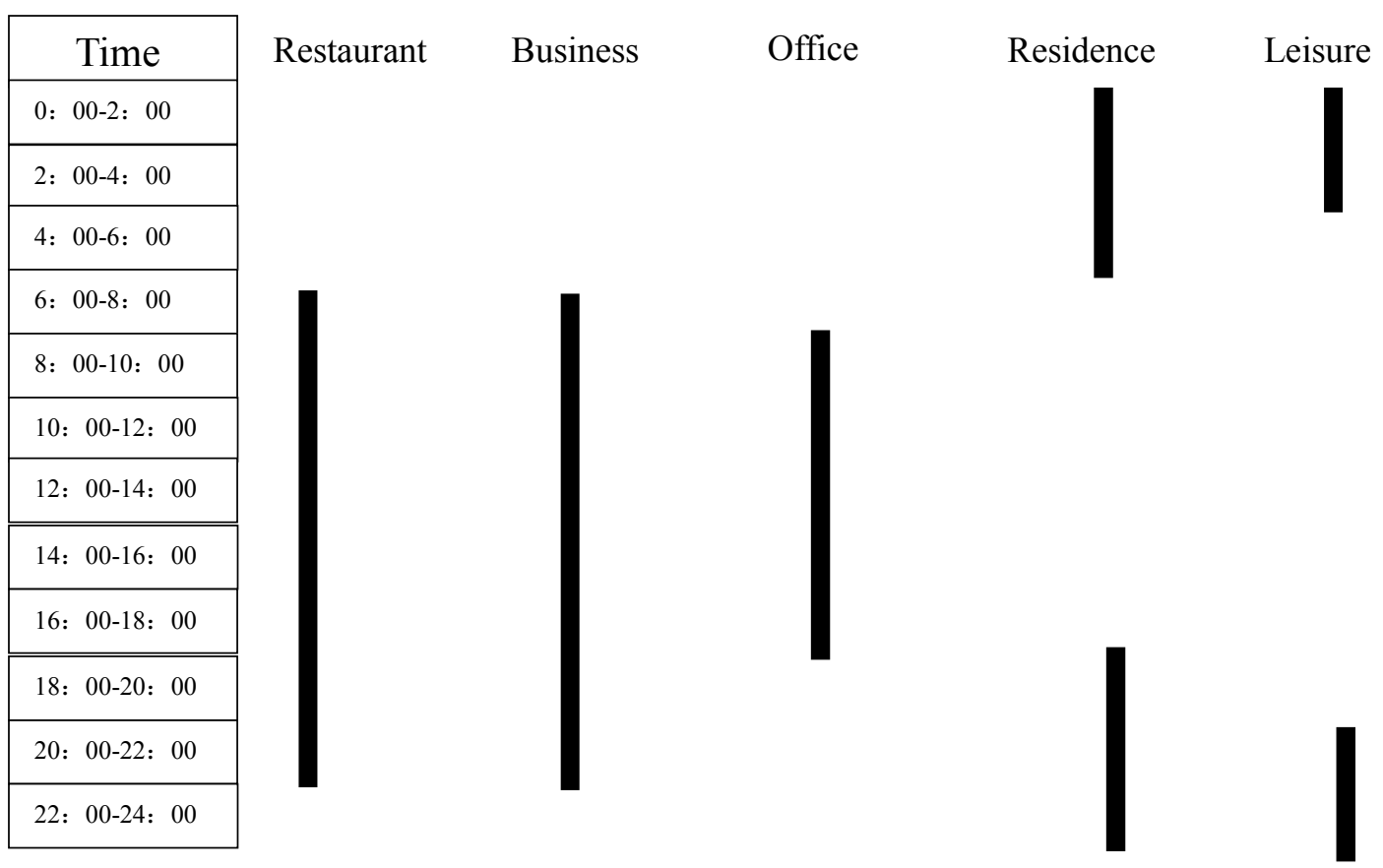

Figure 2. Main traffic use time for different functions

Influence of Functional Zoning on Traffic Parking Demand. Cars are increasing year by year, and the demand for parking lot will increase.

\section{Case Analysis}

Traffic Trip Generation. Qingdao Wanda cinema Residential area accounted for $48 \%$, covers an area of 2.6 million square meters. Commercial functional area of the project covers an area of 2.4 million square meters. Load rate is $90 \%$ in 2017. The recent forecast target year is 2017. The long-term forecast target year is in 2022. It will maintain full load operation in 2022. Relevant data are taken into Eq.1 and Eq.2. The results are shown in Table 1.

Table 1 Project traffic generation forecast results

\begin{tabular}{c|cc}
\hline Year & 2017 & 2022 \\
\hline Functional area & 185615 & 206239 \\
Busidential function & 561600 & 624000 \\
Total traffic generation & 747215 & 830239 \\
\hline
\end{tabular}

Qingdao traffic system requirements: the total number of residents to travel by day now 7.76 million increased to 12.76 million in 2020. Although the data in the table does not exceed the requirements, is still very large. Thus it can be seen that after the completion of all projects in 2017, the traffic attraction and the amount of traffic will be greater.

Traffic Trip Mode. According to the survey results of traffic mode in Qingdao, considering that the project is in the vicinity of the newly built Metro Line 1 and line 6 , this paper predicts the internal and external traffic modes of office and business trips. The results are shown in Fig. 3 and Fig. 4. 


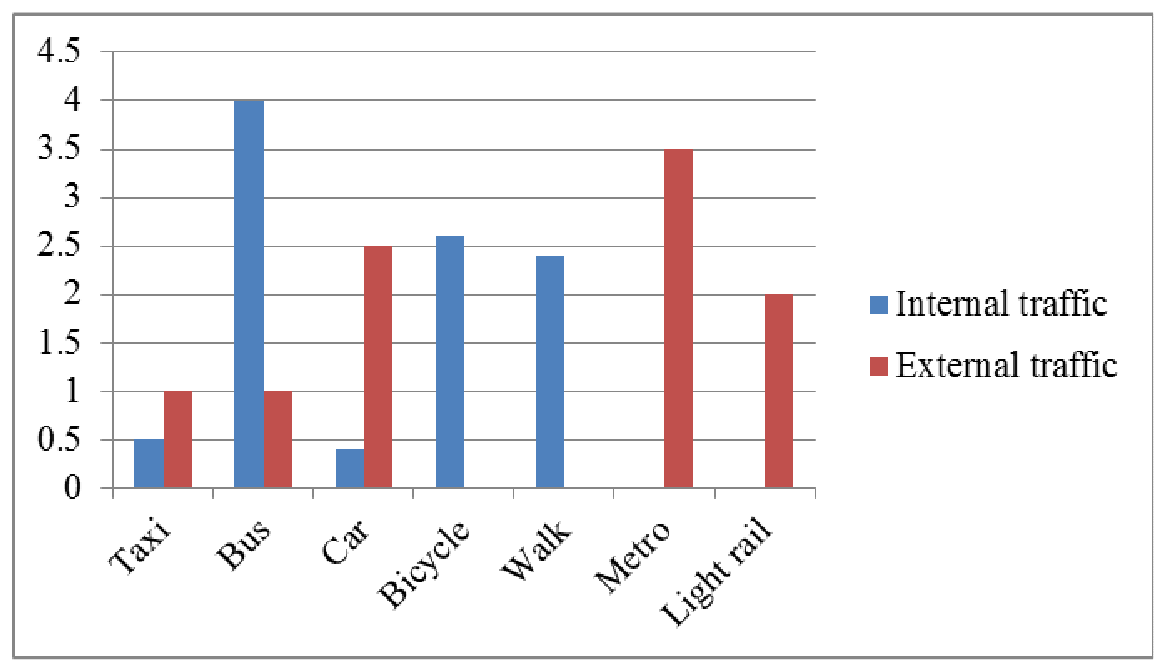

Figure 3. Prediction of office travel mode

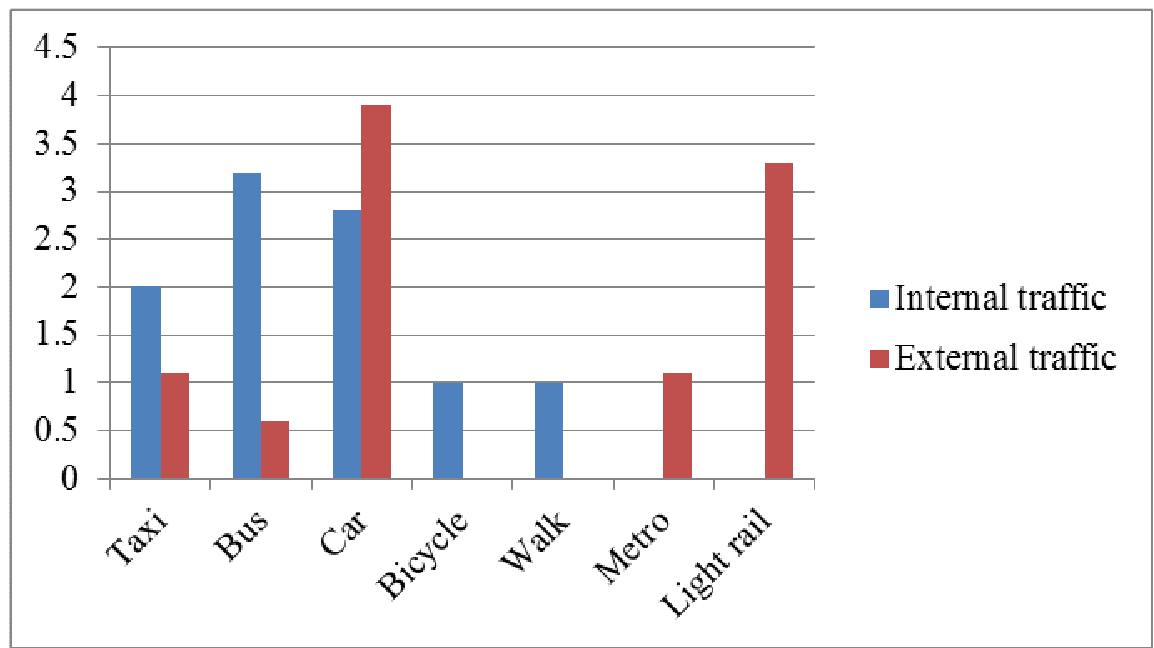

Figure 4. Prediction of business travel mode

The proportion of public transport is relatively large in the way of internal transportation, which is in line with the idea of developing public transportation in Qingdao. The proportion of external transportation in the subway, light rail is significantly larger, because of its rapid economic, large volume, saving time and other unique advantages. In addition, the proportion of private cars also increased significantly.

Traffic Parking Demand. According to the comprehensive traffic planning of Qingdao City, the number of parking spaces in the project is predicted as shown in table 2.

Table 2 Project parking forecast

\begin{tabular}{c|cccc}
\hline Index & $\begin{array}{c}\text { General } \\
\text { index }\end{array}$ & $\begin{array}{c}\text { Selection index } \\
\text { of the project }\end{array}$ & $\begin{array}{c}\text { Covered area or seat } \\
\left.\text { number[m }{ }^{2}\right]\end{array}$ & $\begin{array}{c}\text { Parking } \\
\text { number }\end{array}$ \\
\hline Residential zone & $0.5-1.0$ & 0.5 & 2600000 & 13000 \\
Business zone & $0.6-1.0$ & 0.8 & 400000 & 3200 \\
Yachting Center & $1.0-1.5$ & 1.2 & 50000 & 600 \\
Bar Street & $1.0-1.5$ & 1.2 & 30000 & 360 \\
Convention Center & $3.0-3.5$ & 3 & 2000 & 64 \\
Hospital & $2.0-3.0$ & 2.5 & 30000 & 750 \\
Hotel & $1.2-3.0$ & 2 & 600000 & 12000 \\
\hline
\end{tabular}

It can be seen from the table that there is a great demand for parking in the city complex, which requires reasonable use of the ground and underground space. 


\section{Conclusion}

In this paper, the function of urban complex is analyzed from two aspects: the external traffic system and the internal traffic environment. This paper analyzes the Qingdao Huangdao Wanda Oriental cinema data. The effects of urban complex on trip generation, trip mode, traffic peak hour and parking demand are studied.

This article provides some improvement measures, such as respect for regional traffic situation, separate of traffic flow, avoid peak hours, Set clear guidance, construct of three-dimensional traffic system.

\section{References}

[1] D. Ni: Study on the Theory and Application of Traffic Impact Assessment of Urban Public Building Project (Ph.D., Nanjing Forestry University, China 2009), p.46. (In Chinese)

[2] S. Tan: Study on Traffic Impact Analysis of Large Shopping Mall (Ph.D., Jilin University, China 2007), p87. (In Chinese)

[3] Z.Y. Zou, Y. Xiao and J.Z. Gao: Robustness Analysis of Urban Transit Network Based on Complex Networks Theory, Vol.1 (2013) No.4, p.43.

[4] L. Li: Under the Open Polymerization, City Complex Layout Design, City Planning Forum, Vol.4 (2009) No.5, p.23.

[5] Z. Sun: In the Center of the City Traffic Impact Analysis of Large Scale Public Building Project (Ph.D., Beijing Jiaotong University, China 2007).p.43. (In Chinese)

[6] J. Cao: Study on Traffic Impact Assessment of Residential Construction Project Based on Trans CAD (Ph.D., Jilin University, China 2013), p67. (In Chinese)

[7] J.J. Wang, W. Shen: Urban Complex Traffic Impact Assessment Characteristics, Vol.13 (2012) No.8, p.67.

[8] C.F. Shao: Traffic Planning Theory (Beijing Jiaotong University, China 2010), p.56. (In Chinese)

[9] M. Caler: Proc. International Scientific Conference Urban Civil Engineering and Municipal Facilities (Italy, November 4-6, 2015). Vol.4, p.78.

[10]L. Wang, Liu X.M. Liu and F.T. Fu, Study on Traffic Impact Analysis System of Big Cities, Vol.4 (2015) No.3, p16. 